\title{
Effect of the air press treatment before killing on the delay of rigor mortis in Fish
}

MAKoTO NAGAI, ${ }^{1,2}$ Jo SHINDO ${ }^{2}$ AND HIDEMASA MIKI ${ }^{2}$

'Meijo University, Nagoya 464-8631, Japan (the present) ${ }^{2}$ Kagoshima University, Kagoshima 890-0056, Japan

SUMMARY: It was examined for the living fish taken much more oxygen $\left(\mathrm{O}_{2}\right)$ in the blood before killing by the air press treatment (APT) in the underwater to promote the aerobic metabolism for delaying the rigor mortis of fish body after death. In the cases of eel, tilapia and horse mackerel, the $\mathrm{O}_{2}$ was taken so much as $2.6,1.1$ and $3.3 \mathrm{~mL} / \mathrm{mL}$ in the blood of vine by the APT, which was operated at the absolute pressure of $4.5 \mathrm{kgf} / \mathrm{cm}^{2}$ (ata) for $50 \mathrm{~min}$. Namely, the $\mathrm{O}_{2}$ was 1.3 times as much as that of the each control without APT at 1.0 atmosphere $(\mathrm{atm})$. After the APT, the each fish was killed immediately and stored at $5{ }^{\circ} \mathrm{C}$. As the results, the APT prolonged the each full rigor-mortis achievement-time (FRA) of eel, tilapia and horse mackerel for $23.0 \mathrm{~h}, 6.0 \mathrm{~h}$ and $12.5 \mathrm{~h}$ more than that of the each control, respectively. And their each FRA became $78.0 \mathrm{~h}, 12.5 \mathrm{~h}$ and $24.0 \mathrm{~h}$, respectively. Also, their initial contents of ATP increased to $6.9,4.1$ and $12.6 \mu \mathrm{mol} / \mathrm{g}$ as much as 1.4 times of the each control. Therefore, these results suggested that the APT of fish before killing promoted the recovery of ATP and delayed the rigor mortis.

\section{KEY WORDS: rigor mortis, ATP, air press treatment, glycogen, creatine phosphate}

\section{INTRODUCTION}

The high freshness has been required for the raw fish to be consumed as the products of SASHIMI and SUSHI in Japan. The middleman transports the raw fish to a place of consumption from a fishing ground. If it is possible to transport the raw fish with the higher freshness, the effect on economy will be bigger in the market.

Several researchers have reported about the full rigor-mortis achievement-time (FRA) of fish, which was delayed by the different storage temperatures ${ }^{1,2)}$ or the methods of killing. ${ }^{3-5)}$ Generally, the fish muscle tissue exhibits metabolic changes after death. One of these changes is the ATP decomposition accompanied with rigor-mortis ${ }^{6}$ and the glycogen breakdown through glycolysis with accumulation of lactate.

We have previously reported that the air press treatment (APT) of fish before killing prolonged the FRA. ${ }^{n}$ Because, the delay of rigor mortis may retain the ATP content by the APT before killing and keep it at the high level for a long period due to the ATP recovery in fish muscle after death.

Therefore, the objective of this study was to investigate about the ATP recovery occurred in the muscles of eel, tilapia and house mackerel during $5{ }^{\circ} \mathrm{C}$ storage of the fishes killed after the APT.

\section{MATERIALS AND METHODS}

\section{Materials}

For the sample fishes, eel, tilapia and horse mackerel were obtained from the local fish farm, where they were cultured at the ambient water-temperatures ranging from 16 to $30{ }^{\circ} \mathrm{C}$. These fishes were transported to our laboratory in the tank with water. They were kept in the water at the cultured temperature for a few days until the day used for the experiments.

\section{Air press treatment (APT)}

We applied the Henry's law to increase the air concentration in the water and absorbing more oxygen in the blood of fish. Thus, the APT was carried out to put the air pressure from 2 to 5 absolute pressure (ata) for $50 \mathrm{~min}$ on the living fish in the underwater (water: $10 \mathrm{~L}$ ) inside of the tank (volume: $45 \mathrm{~L}$ ), using the compressor (air: $47 \mathrm{~mL} / \mathrm{min}$ ). During the APT, the bubbling system (flow: $1.58 \mathrm{~L} / \mathrm{min}$ ) was used inside of the tank for constantly supplying the air into the water.

Analytical Methods

Oxygen content in the blood

For the measurement of oxygen $\left(\mathrm{O}_{2}\right)$, the blood was taken as much as $70 \mu \mathrm{L}$ from a vain in the tail, using the capillary glass-tube. Blood oxygen was measured using the Oxygen Measurement Instrument (CHIRON, 348 type).

Rigor index

Rigor-index was measured by the method of Bito et 
al. ${ }^{8)}$

ATP content

For the measurement of ATP contents, the ordinary dorsal muscle was separated partially from the same sample fish before measuring the rigor index of a fish body. The each $2 \mathrm{~g}$ of their muscles was used for the analysis of ATP content. The ATP analysis was used the same method as reported previously. ${ }^{7)}$

Creatine phosphate content

Creatine phosphate was determined for $10 \mu \mathrm{L}$ extract $^{9}$ ' with a TSK gel DEAE-2SW (TOSO) column (flow rate of $1 \mathrm{ml} / \mathrm{min}$ ), using the HPLC (HITACH-7100 type).

\section{Glycogen content}

After $1.0 \mathrm{~g}$ of muscle was put into $5 \mathrm{~mL}$ of heated $30 \%$ potassium hydroxide. And then, $5 \mathrm{~mL}$ of absolute ethanol was added to the solution and the glycogen was precipitated. The obtained glycogen was determined by the method of Somogyi-Nelson. ${ }^{10)}$

\section{RESULTS}

Table 1 shows the $\mathrm{O}_{2}$ contents in the blood of eel, tilapia and horse mackerel after the APT in the underwater at $1.0 \mathrm{~atm}$ and 4.5 ata.

Table $1 . \mathrm{O}_{2}$ Contents in blood of eel, tilapia and horse mackerel treated by the APT.

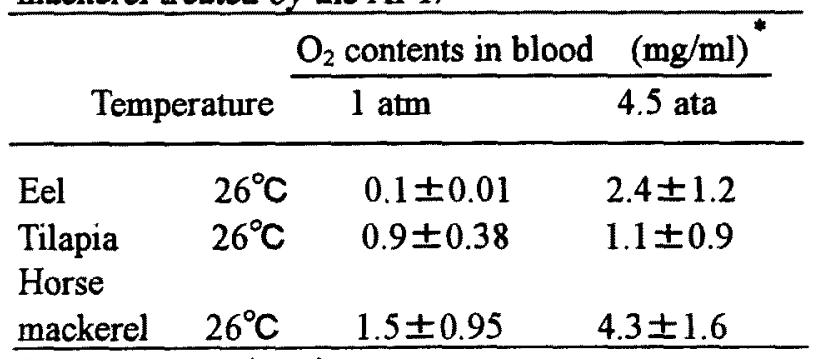

* Mean \pm S.D. $(\mathrm{n}=5)$

By the APT at 4.5 ata, the treated fishes held the amount of $\mathrm{O}_{2}$ as much as 1.3 times of the each control fish $(1 \mathrm{~atm})$ in the blood. As a result, the rigor mortis of each sample fish was delayed individually, compared with the control fishes as shown Fig.1.

In the case of eel, the control indicated almost $100 \%$ of the rigor index at $55 \mathrm{~h}$ (FRA) after killing, but the treated fishes did around $8 \%$ of it at that time. The FRA of the treated fishes was around $78 \mathrm{~h}$. However, the treated fishes indicated $51 \%$ of the rigor index at the FRA.

In the cases of tilapia and horse mackerel, the each control exhibited the full rigor mortis at $5.5 \mathrm{~h}, 11.5 \mathrm{~h}$ after killing, though the treated fishes did around $72 \%$ and $38 \%$, respectively.
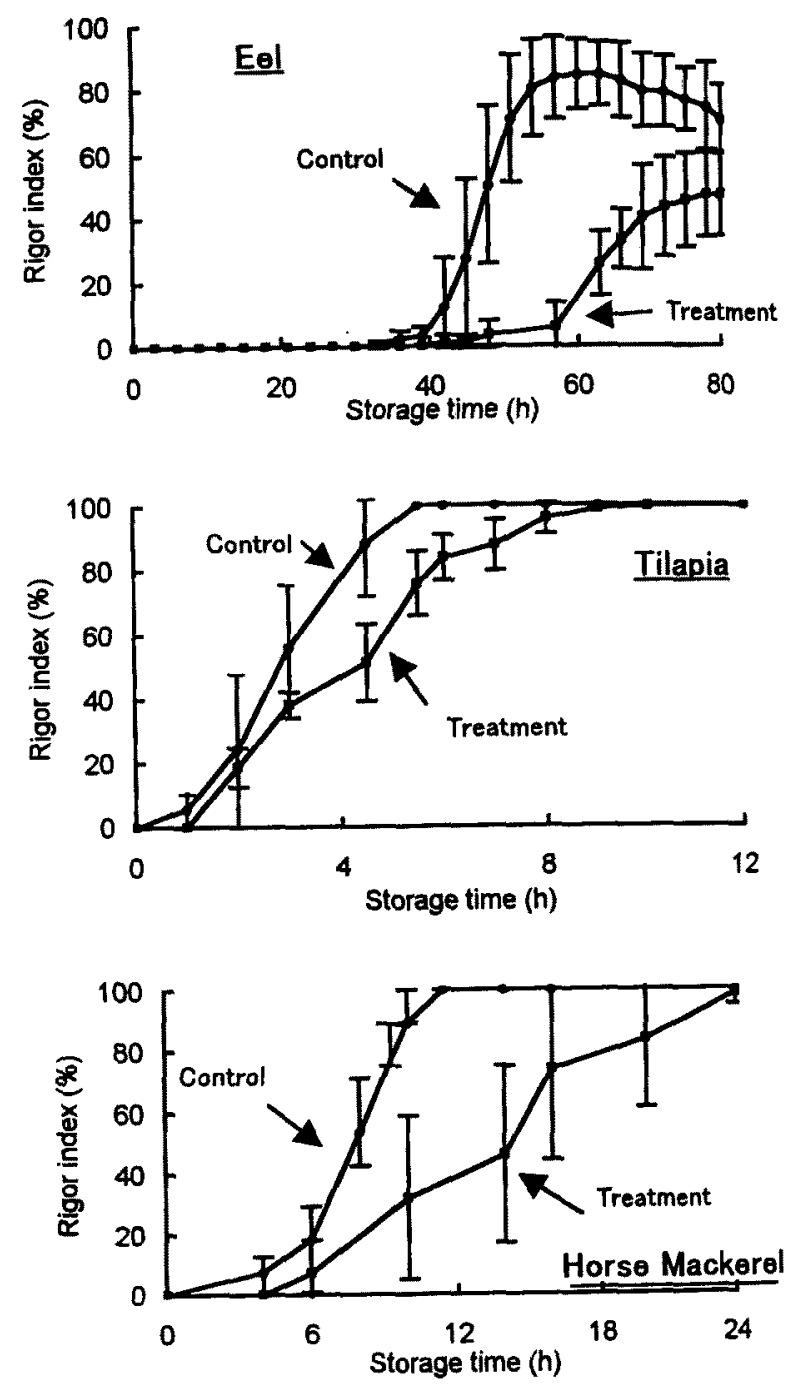

Fig.1 Progress in rigor mortis expressed by rigor index in eel, tilapia and horse mackerel during storage at $5{ }^{\circ} \mathrm{C}$

Also, the treated fishes exhibited the full rigor mortis at $11.5 \mathrm{~h}$ and $24.0 \mathrm{~h}$ after killing, respectively. However, the rigor indices of the controls and treated fishes reached to almost $100 \%$ during storage at $5{ }^{\circ} \mathrm{C}$ each other in tilapia and horse mackerel.

Figure 2 shows the changes in the contents of ATP during storage at $5{ }^{\circ} \mathrm{C}$. The initial ATP contents of eel, tilapia and horse mackerel were around 6.9,4.1 and $12.6 \mu \mathrm{mol} / \mathrm{g}$, respectively.

The ATP contents of treated fishes were maintained at the high levels for longer period than that of the controls, respectively. In the cases of eel and horse mackerel, the sample fishes stored at $5{ }^{\circ} \mathrm{C}$ and maintained the ATP contents constantly around 3.8 and $10.8 \mu \mathrm{mol} / \mathrm{g}$ for $36 \mathrm{~h}$ and $10 \mathrm{~h}$ after killing, respectively. 

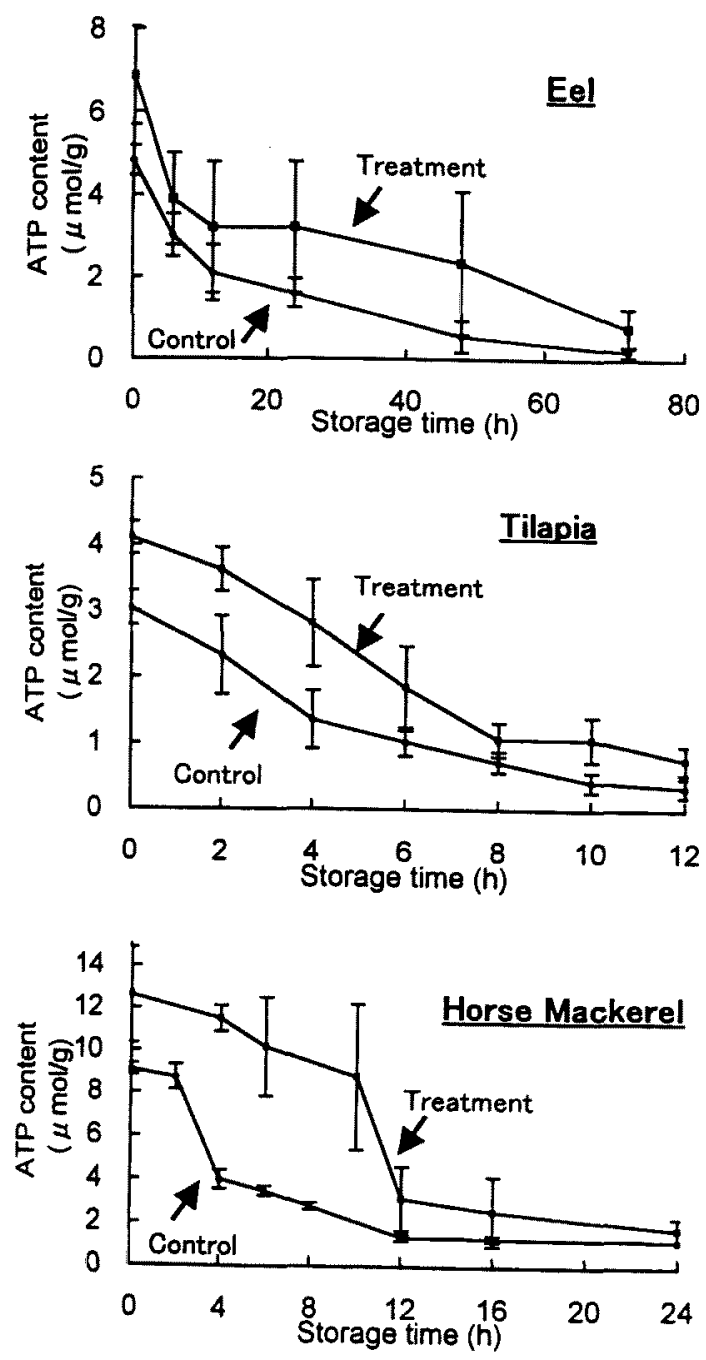

Fig.2 Changes in ATP content in muscles of eel, tilapia and horse mackerel during storage at $5{ }^{\circ} \mathrm{C}$.

As for tilapia, the initial ATP contents of the treated fishes were high as much as $4.1 \mu \mathrm{mol} / \mathrm{g}$. Figure 3 shows the changes in the contents of creatine phosphate during storage at $5{ }^{\circ} \mathrm{C}$. The initial contents of creatine phosphate were $11.3,17.4 \mu \mathrm{mol} / \mathrm{g}$ in eel and horse mackerel, respectively. The creatine phosphate contents of treated fishes decreased much more than that of the controls during storage at $5{ }^{\circ} \mathrm{C}$. The creatine phosphate contents of treated fishes were maintained at the high levels for $6 \mathrm{~h}$ after killing. In the cases of eel and horse mackerel, the treated fishes maintained the creatine phosphate around 11.5 and $16.2 \mu \mathrm{mol} / \mathrm{g}$ after $6 \mathrm{~h}$ of killing, respectively.
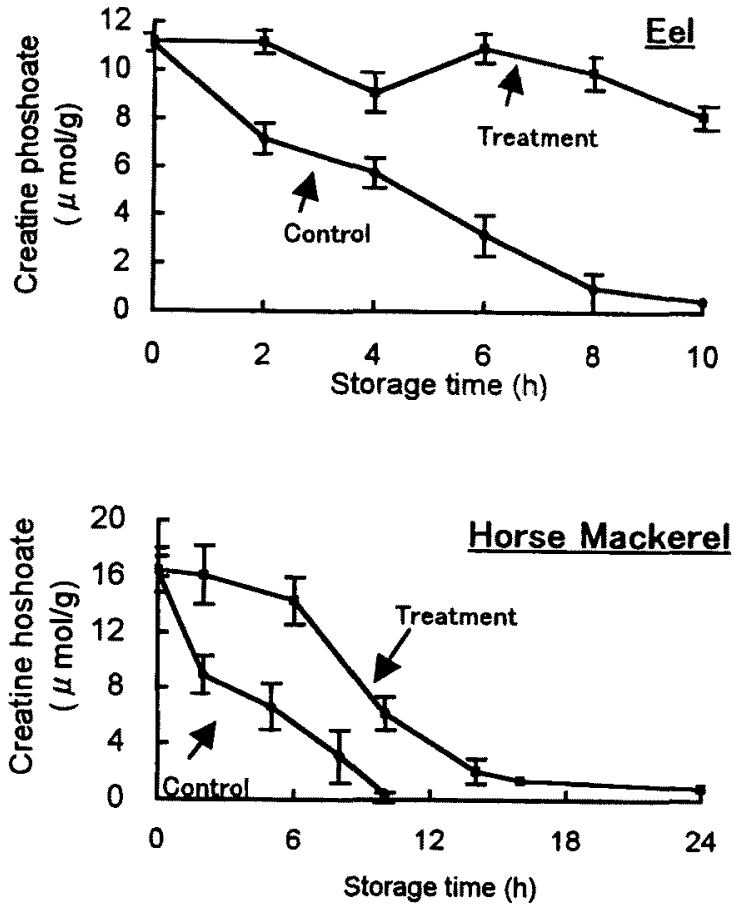

Fig3 Changes in creatine-phosphate contents in muscles of eel, tilapia and horse mackerel during storage at $5{ }^{\circ} \mathrm{C}$.
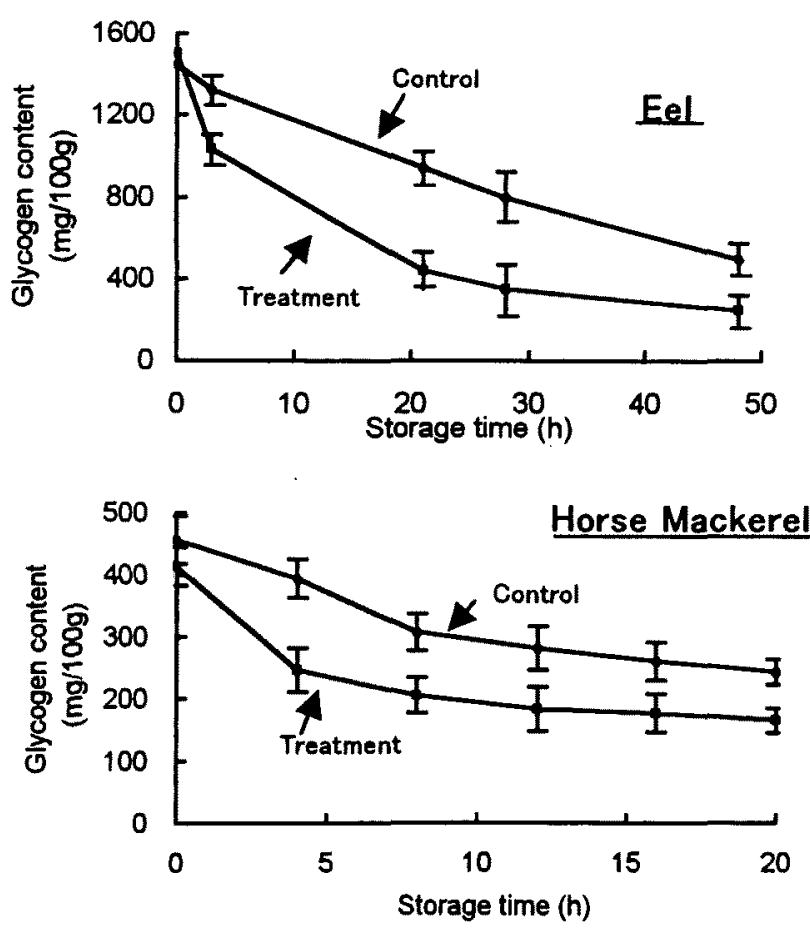

Fig. 4 Changes in glycogen contents in muscles of eel, tilapia and horse mackerel during storage at $5{ }^{\circ} \mathrm{C}$.

Figure 4 shows the changes in the contents of glycogen in the muscles of fishes killed after the APT during storage at $5{ }^{\circ} \mathrm{C}$. The initial glycogen contents of eel and horse mackerel were $1,473,456 \mathrm{mg} / 100 \mathrm{~g}$, respectively. The glycogen of treated fishes was decreased rapidly in the early period of storage. 


\section{DISCUSSION}

The fishes treated by the APT were holding much more oxygen compared with their controls. After killing these treated fishes, their ATP contents were maintained at the high levels as much as around the initial contents in muscles in the early period during storage at $5{ }^{\circ} \mathrm{C}$. While, the whale muscles kept the initial contents of ATP and $\mathrm{pH}$ for a few hours in the aerobic conditions after killing. And then the whale muscles held much oxygen during the onset of rigor mortis. ${ }^{11)}$ We obtained the same results in the fishes treated by the APT as well as whales, as follows. The fishes maintained the ATP contents the high levels as much as around the initial contents in their muscles for several hours in the early period after killing them. During the early period after killing, the creatine phosphate and another phosphate compounds would supply the high energy for ADP (adenosine phosphate) to regenerate ATP. Also, the glycogen would breakdown through glycolysis with accumulation of the lactate in the anaerobic conditions.

Furthermore, the APT accelerated for the treated fish to increase the initial ATP content at more high level and maintain its level for a longer time in the early period after killing, comparing the control fish without the APT. At the same time, the treated fishes of horse mackerel kept the creatine phosphate for $6 \mathrm{~h}$. But, the glycogen of treated fishes decreased faster than that of the control in the early period after killing. As the results, it would be considered that the energy of ATP recovery depended on the glycogen breakdown through glycolysis in the anerobic condition. Therefore, these results suggested that the APT of the living fish promoted the recovery of ATP and delayed the rigor mortis after killing.

Hereafter, it would be possible from the obtained results that the APT applies for the high freshness distribution of instantly killed fishes and the dry transportation of living fishes without ambient water.

\section{REFERENCES}

1. Mochizuki S, Ueno Y, Sato K, Hida N. Effects of storage temperatures on post-mortem changes in the muscle of chub mackerel. Nippon Suisan Gakkaishi 1999; 65: 495-500.

2. Iwamoto $M$, Yamanaka $H$. Watabe $S$ and Hashimoto $\mathrm{K}$. Effects of storage temperature on rigor mortis and ATP degradation in plaice muscle. J. Food. Sci.1987; 52:1514-1517.

3. Mochizuki S, Sato A. Effects of various killing procedures and storage temperatures on post-mortem changes in the muscle of horse mackerel. Nippon Suisan Gakkaishi 1994; 60: $125-130$.

4. Abe H. Okuma E. Rigor-mortis progress of carp acclimated to different water temperatures. Nippon Suisan Gakkaishi 1991; 57: 2095-2100.

5. Hwang $\mathrm{G}-\mathrm{C}$, Ushio $\mathrm{H}$, Watabe $\mathrm{S}$, Iwamoto $\mathrm{M}$, Hashimoto $\mathrm{K}$. The effect of thermal acclimation on rigor mortis progress of carp stored at different temperature. Nippon Suisan Gakkaishi 1991; 57: 541-548.

6. Bate-smith E.C. Bendall J.R. Changes in muscles after death Brit. Med. Bull. 1956; 12: 230-235.

7. Nagai M, Shindo J, Miki $H$. Effect of air press treatment before Killing on the delay of post - mortem of Eel and Tilapia. Nippon Suisan Gakkaishi 2001; 67:286-290.

8. Bito M, Yamada K, Mikumo Y, Amano K. Sakana no sigokoutyoku ni kannsuru kennkyuu (In Japanese) Bull.Tokai. Reg.Fis.Res.Lab., 1983;109:89-96.

9. Matsumoto M, Yamanaka H. Post-mortem biochemical changes in the muscle of kuruma prawn during storage, and evaluation of the freshness. Nippon Suisan Gakkaishi 1990; 56:1145-1149.

10. Somogyi M. Notes on sugar determination. J. Biol. Chem. 1952; 195: 19-23.

11. Marsh $\mathrm{BB}$. Observation on rigor mortis in whale muscle. Biochim. Biophys. Acta. 1952; 9: 27-132. 